\title{
Moralitas Dan Spiritualitas Islam Sebagai Arah Reformasi Pendidikan
}

\author{
Hj. Siti Kusrini
}

Penulis adalah Dosen Fak. Tarbiyah Universitas Islam Negeri (UIN) Malang

\begin{abstract}
To face the challenge of globalization era, moslems in Indonesia begin to have sympathy and moral obligation, since Islam is a teaching that becomes hudan (guidance) toward the reforms of all aspects of life. It expects a society, the supremacy of which, is in God's hand. While the human being must surrender to and worship to God. To face the 21 st century, Islamic ethics and moral are required to create the expected civilized society. Therefore, the moslems must be able to identify the dimension of ethical and social values that can guide its followers to conduct moral reasoning or ijtihad, in order to realize the development of the expected civilized society.
\end{abstract}

\section{Pendahuluan}

Perkembangan dan kemajuan IPTEKS saat ini melahirkan budaya teknologi yang membuat manusia sangat tergantung pada hasil ciptaannya. Akibatnya kehidupan menjadi subjektif, instrumental, sarat dengan pertentangan, serba rasional, padat ketimpangan dan kesenjangan. Hal ini berakibat timbulnya penyakit psikologis dan sosial, a.l. kecemburuan sosial, kemiskinan, bunuh diri, letupan sosial, stres dsb. Budaya hidup yang berlandaskan kebersamaan, kekeluargaan, tenggang rasa, kewajiban moral dsb. tergeser oleh budaya hidup mekanistik yang berlandaskan 
perhitungan rasional dan untung rugi, sehingga akhimya muncul liberalisme. Dengan demikian kekuatan akal digunakan sebagai obor petunjuk arah kehidupan, sehingga muncullah berhala baru, karena manusia mulai menuhankan segala ciptaannya yang mempesona. Hal ini menimbulkan kegoncangan dan ketimpangan, karena penerapan nilai-nilai baru yang belum mapan tetapi nilai-nilai lama (adat, tradisi) mulai ditinggalkan.

Dalam menghadapi tantangan era globalisasi ini umat Islam di Indonesia mulai prihatin dan mempunyai kewajiban moral karena Islam adalah suatu ajaran yang merupakan hudan (petunjuk) untuk melakukan reformasi dalam segala bidang kehidupan yang secara jelas mendambakan masyarakat di mana supremasi berada di tangan Allah sedangkan manusia harus berserah diri dan mengabdi kepadaNya. Beban umat Islam di Indonesia dewasa ini adalah bagaimana meningkatkan peran dirinya agar menjadi manusia yang lebih berarti di muka bumi ini, dapat melaksanakan perbaikan, mempunyai semangat kerja dan pengabdian yang tinggi. Umat Islam harus berupaya mengembangkan iman dan taqwa kepada Allah SWT dan diimbangi dengan pengembangan ilmu agar mempunyai harkat martabat yang tinggi sesuai dengan petunjuk Allah dalam Surat Almujaadillah ayat 11. Dengan demikian dapat dikemukakan bahwa untuk menghadapi abad ke-21 dibutuhkan etika dan moral Islam dalam melaksanakan reformasi untuk menciptakan masyarakat madani yang didambakan. Oleh karena itu umat Islam harus mampu mengidentifikasi segi nilai etis dan sosial yang mampu membina umatnya untuk melakukan penalaran akhlaq (moral reasoning) atau juga disebut ijtihad agar dapat mewujudkan pengembangan masyarakat madani yang diidamkan. Demikian jelaslah bahwa Islam secara fungsional mengandung ajaran dan berbagai usaha serta cara untuk memecahkan masalah kehidupan perorangan maupun kehidupan bersama. Islam dapat membimbing gerak dinamis umat manusia sehingga tidak tersesat dan mengajak manusia menemukan jati dirinya yang mulia (Mulkhan, 1993:5). Dengan memperoleh arahan tentang moralitas Islam ini menjadi kewajiban muslim untuk menghayati unsur-unsur moralitas itu dalam dirinya dan digunakan sebagai kebiasaan untuk bertindak atau berperan dalam masyarakat. Sementara itu aspek atau segi spiritualitas Islam mengandung ajaran tentang bagaimana manusia itu sebaiknya memiliki pengetahuan, mengalami perkembangan, dan memerankan dirinya sebagai muslim. Pengetahuan ini meliputi pengetahuan tentang dirinya sendiri, pengetahuan tentang Tuhan, tentang dunia fana, tentang dunia baqa, tentang tiga

Ulul Albab, Vol. 4 No. 1, 2003 
tahap perkembangan yang dialami manusia, tugas utama yang harus diperankan dan akhirnya seluruhnya mengarah kepada kemampuan untuk selalu ingat dan cinta kepada Allah.

Demikianlah petunjuk moralitas dan spiritualitas Islam dalam reformasi kehidupan bermasyarakat. Apabila muslim mau melaksanakan petunjuk tsb. maka segala masalah yang dihadapi dapat dipecahkan dengan menggunakan kekuatan ilmu yang disinari iman. Hal ini sesuai dengan firman Allah dalam Surat Insyirah ayat 6-8:

Inna ma'al usri yusraa.

Fa idzaa faraghta fanshab.

Wa illa Rabbika farghab.

Dari ayat tsb. jelaslah bahwa Islam memberi jalan keluar untuk mengatasi segala kesulitan yang dihadapi dalam kehidupan bersama, baik masalah yang fundamental maupun masalah yang praktis. Untuk itu maka perlu dikaji bagaimana moralitas dan spiritualitas Islam dalam memberi petunjuk perilaku dan arah moral untuk menghadapi perkembangan dan perubahan yang terjadi dewasa ini.

\section{Permasalahan}

Keadaan masyarakat Indonesia yang saat ini sedang mengalami reformasi dalam segala bidang kehidupan timbul permasalahan sbb.:

1. Bagaimanakah petunjuk moralitas dan spiritualitas Islam yang berkaitan dengan reformasi pendidikan?

2. Bagaimanakah sikap umat Islam terhadapnilai-nilai supranatural traaansendental bagi reformasi pendidikan?

\section{Pembahasan}

\section{Petunjuk moralitas dan spiritualitas Islam yang berkaitan dengan reformasi hidup bermasyarakat.}

Islam telah menanamkan dasar kebenaran yang fundamental yang dipatuhi dan dihormati dalam segala keadaan. Kebenaran tsb. dapat diwujudkan oleh setiap 
individu dalam kehidupan bersama. Islam menjaga keselamatan dengan sistem moral yang efektif, memberi petunjuk dasar-dasar pokok kebajikan seperti tercantum dalam Surat $\dot{A} 1$ Baqarah ayat 177 yang artinya sbb.:

Bukanlah termasuk golongan kebajikan menghadapkan muka ke arah timur dan barat, tetapi yang termasuk golongan kebajikan ialah beriman kepada Allah, hari akhir, malaikat-malaikat, Kitab-Kitab, Nabi-Nabi, memberikan bantuan harta yang disayanginya kepada kerabat, anak-anak yatim, orang-orang miskin, orangorang yang terlantar dalam perjalanan, peminta-minta, dan memerdekakan perbudakan, mengerjakan shalat, menunaikan zakat, menepati janji yang telah diperbuat, sabar menderita kemiskinan dan kemelaratan, terutama ketika perang. Itulah orang-orang yang benar keimanannya dan itu pulalah orang-orang yang taqwa.

Ayat tsb. memberi petunjuk secara rinci tentang kebajikan yang harus dilakukan oleh setiap individu dengan tekun. Dalam ayat tsb. ditunjukkan bagaimana mencintai Allah dan mencintai sesama manusia. Setiap orang dituntut untuk beramal baik terhadap sesamanya dan mewujudkan diri sebagai warga dan pendukung yang baik dalam pranata sosial. Dengan demikian setiap muslim memiliki kesetiaan yang kokoh dan tak tergoyahkan dalam keadaan apapun. Dari uraian tsb. jelaslah bahwa Islam memberikan standar tingkah laku yang diklasifikasikan baik dan buruk, benar dan salah, haq dan batal, diridhai dan dikutuk oleh Allah SWT. Jadi moralitas Islami bersifat menyeluruh, bulat dan terpadu, artinya suatu kebulatan nilai dalam moralitas itu mengandung aspek normatif dan aspek operatif yang keduanya menjadi landasan amal perbuatan manusia. Dari segi opratif nilai tsb. mengandung lima kategorial sbb. (Arifin, 1987:140): (1) wajib atau fardhu, (2) sunnah, (3) mubah, (4) makruh, dan (5) haram. Demikianlah Islam menjanjikan sistem moral dan keselamatan bagi umatnya dalam menghadapi masalah baik yang fundamental maupun praktis. Dapat dipahami bahwa Islam mengandung ajaran moral, artinya Islam mengandung rangkaian aturan dan ketetapan bagi pemeluknya tentang bagaimana harus hidup dan bertindak agar menjadi manusia yang baik. Dengan kata lain Islam memberi petunjuk hidupyang baik dan benaryang diridhai Allah, dengan memberikan prinsipprinsip kepribadian manusia yang mencakup bidang moralitas dan spiritualitas. Moralitas Islam mengandung prinsip-prinsip dasar etika muslim yang terdiri dari hukum dasar tentang keutamaan. Moralitas ini menjadi ciri khas manusia yang tidak ditemukan pada makhluk lain di bawah derajat manusia. Ciri khas tsb. ialah kesadaran moral, yaitu kesanggupan melakukan hal yang baik dan menyingkiri hal

Ulul Albab, Vol. 4 No. 1, 2003 
yang buruk untuk kepentingan diri dan masyarakatnya. Moral Islam sangat kokoh keberadaannya karena memberikan fadhillah atau keutamaan yang erat kaitannya dengan hakikat manusia sehingga akan menandai manusia di segala jaman. Moralitas Islam bersumber dari watak tabi'y manusia yang merupakan dorongan batin manusia dengan fitrahnya merasa wajib berbuat kebajikan bagi dirinya maupun sesamanya. Kesadaran moral memberikan kekuatan konstruktif dan positif yang bersinambungan untuk pengembangan pribadi manusia. Secara rinci Islam memberikan uraian tentang moral utama yang sampai saat ini masih dipegang teguh dalam peradaban maju, yaitu kesucian, keikhlasan, kejujuran, kerendahan hati, keadilan, kesabaran, keterbukaan, menepati janji, kesedrhanaan, kesopanan, kelembutan hati, pemaaf, keberanian, kebijakan dan pengendalian diri. Demikianlah Islam memberi petunjuk dan arah kepada manusia demi kebaikan diri dan sesamanya agar mampu menciptakan peradaban yang tinggi. Menyempurnakan peradaban dapat ditempuh dengan menyelaraskan ilmu, seni, dan moral yang baik. Oleh karena itu Amrullah \& Hadimi (1998:1) berpendapat bahwa muslim perlu belajar Islamic knowledge yang terbagi menjadi dua cabang, yaitu religious knowledge dan scientific knowledge. Scientific knowledge disebut hikmat atau kebijaksanaan yang sangat berguna untuk pembangunan ilmu dan teknologi. Sedangkan religious knowledge sebagai pengendali scientific knowledge karena membimbing pengembangan budi nurani manusia. Menurut para ahli Islam, Allah SWT menciptakan bagian yang penting dalam diri manusia yaitu: aql, qalb, dan nafs. Masing-masing mempunyai fungsi yang saling kait-mengait: aql berfungsi untuk memahami ilmu Islam yang berkaitan dengan hal baik dan buruk sesuai dengan perintah Allah, sehingga dapat menghubungkan kebaikan yang diajarkan Allah kepada qalb. Sedangkan qalb memutuskan secara harmonis untuk berbuat baik atau buruk yang disebut akhlaq. Adapun nafs adalah kesenangan secara berlebihan terhadap keduaniawian tanpa memikirkan baik, buruk, berbahaya, tak berguna, dan bertentangan dengan kehendak Allah. Dengan kata lain nafs ini pekerjaannya menipu qalb. Dapat dipahami bahwa memperkuat aql sama pentingnya dengan memperkuat $q a l b$. Adapun cara memperkuat $a q l$ dengan mempelajari pengetahuan Islam, sedangkan memperkuat qalb atau membersihkan diri dapat dilakukan dengan cara melaksanakan perintah Allah sehingga membina perasaan ikhlas. Dengan qalb yang telah bersih tsb. aql dapat menyadari perbuatan yang sesuai dengan kehendak Allah dan mau mengikutinya sebagai kebiasaan berpikir yang baik dan 
benar. Dapat dikatakan bahwa qalb adalah bagian yang terpenting karena menjadi pemimpin seluruh organ tubuh sesuaidengan Hadis Nabi yang terjemahannya sbb.: Di dalam tubuhmu ada segumpal daging, kalau dia baik, baiklah seluruh tubuhmu, kalau dia rusak maka rusaklah seluruh tubuhmu. Dia adalah qalb.

Menurut Azhim (1989:16) untuk memperoleh ilmu pengetahuan, Islam menawarkan metode ilmiah, realistis, artinya metode tsb. ditopang oleh dua faktor, yaitu pewarisan pengalaman dan pemikiran logis. Dengan demikian Islam memberi petunjuk secara jelas bahwa ilmu mempunyai kedudukan yang sangat penting sehingga Rasulullah menyatakan sabdanya bahwa menuntut ilmu wajib bagi setiap muslim, laki-laki ataupun perempuan. Bagi kaum muslim ilmu adalah alat untuk mengkaji masalah yang dihadapinya dan untuk mencari pemecahan secara konkret. Dengan ilmu manusia dapat memperoleh kebenaran sesuai dengan jangkauan akalnya. Kebenaran yang diperoleh melalui akal ini dapat membentuk sikap ilmiah. Apabila sikap ilmiah ini dilandasi oleh iman maka manusia dapat bersifat khanif, yaitu dalam memecahkan masalah selalu menggunakan cara berpuikir ilmiah yang disinari iman sehingga dapat menemukan kebenaran tertinggi.

Untuk melaksanakan keimanan dan ketaqwaan manusia kepada Allah SWT ada lima pilar utama yang harus dijalankan oleh muslim yaitu:

1. pilar pertama adalah syahadat yang berisi dua bagian yaitu (a) pengakuan kepada Allah Maha Kuasa, Maha Pencipta, dan Penguasa alam semesta, (b) mengakui bahwa Muhammad Rasulullah. Dengan mengucapkan syahadat muslim mengakui Allah Pencipta Tunggal segala sesuatu dan Maha Kuasa yang mempunyai konsekuensi bahwa setiap muslim mendekatkan pikiran, perasaannya hanya kepada Allah yang berwujud kesetiaan, pengabdian, tunduk, percaya, berserah diri, dan memuja Allah SWT. Kemudian percaya bahwa Rasulullah Muhammad membiumbing perilaku manusia yang baik dan benar yang diridhai Allah SWT. Hal demikian dapat menjadi komitmen bagi segala perilaku muslim dalam kehidupan bersama sesuai dengan janji manusia terhadap Tuhan seperti tercantum dalam Surat Al A'raaf ayat 172. Karena mengakui Allah Maha Tahu maka manusia dapat mengendalikan perilaku dengan baik, karena segala pikiran dan perilakunya selalu diketahui oleh Allah.

2. Pilar kedua adalah shalat yang merupakan tiang agama. Shalat merupakan salah satu cara manusia untuk secara langsung berkomunikasi dengan Allah SWT. Hal ini merupakan langkah pertama dalam mencapai kemajuan rokhani

Ulul Albab, Vol. 4 No. 1, 2003 
yang paling tinggi. Dengan melakukan shalat manusia dapat memelihara hubungan yang bersinambungan dengan Allah SWT sehingga terhindar dari perbuatan buruk (bersih dari dosa). Di samping itu shalat dapat membina sifat disiplin, taqwa, tenggang rasa, kekeluargaan, persamaan, dan tanggung jawab.

3. Pilar ketiga adalah saum. Dengan melakukan saum atau puasa secara benar sesuai dengan petunjuk maka muslim dapat memperoleh manfaat bagi perkembangan baik fisik maupun mental seperti: kesehatan, pengendalian diri, disiplin, percaya diri, sabar, jujur, tenggang rasa dan tanggung jawab.

4. Pilar yang keempat adalah zakat, yaitu kerelaan memberikan sebagian miliknya untuk orang lain secara ikhlas. Perbuatan ini dilandasi oleh kepercayaan muslim bahwa segala sesuatu milik Allah, dan harta yang dimiliki oleh manusia itu adalah kepercayaan dari Allah yang digunakan untuk kesejahteraan bersama. Dengan melaksanan zakat muslim memperoleh manfaat: membersihkan diri dari sifat kikir dan tamak, membentuk keikhlasan, tolong-menolong, disiplin, kasih sayang, kesejahteraan, tenggang rasa, dan tanggung jawab.

5. Pilar kelima ialah haj, melaksanakan perintah Allah berziarah ke tanah suci (haji). Dengan melaksanakan ibadah haji ini muslim dapat memperluas wawasannya serta terbentuk sifat kebersamaan, kekeluargaan, tolongmenolong, tenggang rasa, disiplin dan pengendalian diri.

Kelima pilar tsb. merupakan tiang utama penyangga operatif dari moralitas Islam yang memberi petunjuk perilaku secara berurutan dan bersinambungan sehingga dapat membentuk pribadi muslim seutuhnya. Dengan demikian kepribadian muslim dapat diukur dengan kenyataan seberapa banyak ia merealisasi potensi martabat kemanusiaannya dalam tingkah laku hidup sehari-hari. Selain kelima pilar tsb. Rasulullah juga mewajibkan muslim a.l.: (1) menuntut ilmu, (2) membudayakan rasa malu, (3) menjaga keseimbangan dunia-akhirat, (4) mengendalikan diri, (5) membersihkan diri dari sifat kikir dan tamak, dan (6) menjaga lidah. Kewajiban tsb. untuk menjaga harkat martabat manusia menjadi tinggi sehingga mampu membimbing diri dan sesamanya ke arah kehidupan yang utama.

Demikianlah internalisasi moralitas Islam secara berangsu-angsur dapat membina setiap muslim untuk beriman kepada Allah SWT dan Hari Akhir. Kesemuanya merupakan spirit untuk mewujudkan kehidupan bersama yang dilandasi moralyang tinggi. Penerapan prinsip-prinsip moral Islam mencakup seluruh 
bidang kehidupan, sejak dari buaian sampai ke liang lahat. Inilah yang menjadikan jaminan dan meyakinkan bahwa moralitas Islam dapat dijadikan pedoman perilaku hidup sehari-hari. Jelaslah bahwa Islam mempunyai tujuan utama yang luhur dan suci yaitu setiap individu dapat membentuk kata hati agar dapat bersikap amar ma'ruf nahi munkar, sehingga mereka memperoleh sorga sebagaimana dijanjikan oleh Allah SWT dalam firmanNya Surat Ali Imran ayat 133-134 yang memerintahkan bagi setiap pribadi untuk berlomba berbuat kebajikan yang menyebabkan pengampunan dari Allah dan merupakan jalan masuk ke sorga bagi orang yang taqwa yaitu orang-orang: (a) menafkahkan hartanya di waktu senang dan susah, (b) menahan amarah, (c) pemaaf, (d) berbuat kebajikan, dan (e) memohon ampun kepada Allah atas perbuatannya yang keji. Jadi Islam sangat menekankan pendidikan disiplin diri agar setiap individu memiliki pribadi uswatun hasanah, yaitu pribadi yang memahami kewajiban dan kebajikan. Pribadi semacam inilah yang mampu menciptakan keseimbangan antara hak individu dan kebaikan bersama dari masyarakat. Dengan demikian timbullah tatanan sosial yang mampu menyerap perubahan-perubahan positif dalam mengembangkan nilai budaya bangsa. Islam menghendaki terbentuknya pribadi yang produktif, kritis, inovatif, dan kreatif dalam menopang nilai-nilai budaya dan peradaabannya agar dapat mewujudkan dirinya sebagai khalifatullah yang membawa misi rahmatan lil alaamin sehingga dapat terwujud perdamaian dunia.

\section{Sikap umat Islam terhadap nilai-nilai supranatural transendental bagi refor-masi pendidikan}

Pendidikan semasa Orde Baru nierupakan pendidikan sentralistik dan otoriter. Praksis pendidikan diarahkan kepada proses indoktrinasi sehingga spektrum pengembangan intelegensi manusia dibatasi hanya untuk teknologi, sedangkan intelegensi emosional, moral, interpersonal, dan intra personal diabaikan. Hal ini mengakibatkan timbulnya krisis kebudayaan di mana kehidupan manusia dikuasai oleh keserakahan, kekerasan, kekejaman, kebodohan, kejahatan, dan kemiskinan. Dengan demikian pendidikan masa Orde Baru menghasilkan manusia-manusia buaya yang tidak berbudaya (Tilaar, 2000:51), artinya manusia tanpa disiplin yang menerapkan hukumnya sendiri dan kehilangan pertimbangan akal sehat. Manusiamanusia tsb. sangat berbahaya karena menimbulkan krisis dalam bidang pendidikan.

Ulul Albab, Vol. 4 No. 1, 2003 
Sehubungan dengan hal tsb. maka manusia Indonesia saat ini melakukan reformasi dalam bidang pendidikan, yaitu suatu upaya untuk melahirkan kembali manusia-manusia yang berbudaya dan beradab, dengan menata kembali nilai-nilai kemanusiaan yang diwujudkan dalam kehidupan politik, ekonomi, dan hukum dalam masyarakat. Dengan demikian reformasi pendidikan adalah suatu upaya untuk menyusun paradigma baru pendidikan nasional. Paradigma tsb. mengarah kepada lahirnya bangsa Indonesia yang bersatu serta demokratis. Oleh sebab itu penyelenggaraan pendidikan harus mampu mengembangkan kemampuan untuk berkompetisi dalam kerjasama, mengembangkan sikap inovatif, dan meningkatkan kualitas hidup. Nampak jelaslah bahwa pendidikan mempunyai intisari pemanusiaan manusia atau proses hominisasi dan humanisasi. Dengan demikian daptlah dipahami bahwa pendidikan adalah suatu perbuatan fundamental yang berpangkal dari jiwa dan hati manusia untuk mengubah, menentukan, dan mengkonstruir hidup manusia (Drijarkara, 1980:87). Jadi hakikat, tujuan, metode, dan sistem nilai yang terkandung dalam pesan-pesan pendidikan merupakan keharusan untuk selalu dirujukkan kepada ajaranagama dan etika. Karena reformasi menyangkut perubahan sosial dan budaya yang banyak digunakan oleg berbagai pihak untuk menawarkan berbagai ideologi sebagai obat penyelamat maka etika sangat dibutuhkan dalam reformasi sebagai usaha manusia untuk menggunakan akal budi dan daya pikirnya dalam memecahkan masalah bagaimana manusia harus hidup yang baik.Sedangkan ajaran agama untuk menemukan dasar kemantapan terhadap perintah atau hukum yang termuat dalam wahyu dan masalah moral baru yang tidak termuat dalam wahyu. Karena Islam sebagai hudan (petunjuk) dengan rentangan sistem nilai memberi petunjuk perilaku yang dapat menciptakan kekuatan seimbang antara akal, qolb, dan nafsu, sehingga mewujudkan suara hati (hati nurani) yang bening dan jernih maka umat Islam juga membutuhkan etika agar dapat menginterpretasikan wahyu sebagai dasar yang mantap untuk berpartisipasi dalam semua dimensi kehidupan masyarakat yang sedang melakukan reformasi. Apabila manusia jemih budi nuraninya maka manusia dapat membedakan yang haq dan batil sehingga dapat mengaktualisasi diri sesuai dengan firman Allah amar ma'ruf nahi munkar, mengerjakan segala perintahnya dan menjauhi laranganNya. Dengan demikian nampak jelas bahwa moralitas dan spiritualitas Islam meletakkan kaidah dan dasar-dasar pendidikan manusia yang ideal dengan mengarahkan konsep hidup untuk mencapai ketinggian spiritual, moral, dan intelektual. Islam memberikan gambaran bahwa manusia adalah makhluk yang

Ulul Albab, Vol. 4 No. 1, 2003 
merdeka (bebas menentukan pilihan) dan menduduki tempat terhormat di antara makhluk lainnya. Manusia dianjurkan agar menemukan esensi dirinya, memikirkan kedudukan dalam struktur realitas, sehingga mampu menempatkan dirinya sesuai dengan keberadaan dirinya. Manusia hanya berarti bila ia berfungsi sebagai makhluk terpadu yaitu dimensi kepribadiannya mencakup dzikir dan pikir. Berdzikir berfungsi untuk menenangkan qolb karena dengan qolb yang tenang dapat memberikan kekuatan yang seimbang dalam menumbuhkan keutamaan atau fadhillah yang berpangkal kepada empat keutamaan induk yaitu: bijaksana, berani, perwira dan adil (Musa,1980:208). Fungsi berpikir untuk menyusun konsep dimana peran kreativitas subjektif manusia dapat memunculkan teori-teori dalam usahanya menyusun the body of knowledge (kerangka ilmu pengetahuan). Demikianlah moralitas dan spiritualitas Islam berperan dalam reformasi pendidikan dalam mengarungi abad ke-21 ini. Islam memberikan landasan etis bagi pengembangan pikiran manusia agar terbuka cakrawala pandang yang menjangkau berbagai aspek kehidupan yang dapat digunakan untuk memakmurkan hidup manusia di bumi ini. Namun demikian semuanya tergantung pada komitmen umat Islam dalam mengejawantah nilai-nilai budaya Islam bagi pendidikan manusia seutuhnya, yaitu mencakup: (1) bagaimana agar peradaban manusia tidak terlepas dari nilai-nilai supranatural transendental, (2) bagaimana para pemeluk Islam berperan dalam setiap gelombang perubahan secara dinamis, aktif dan kreatif; sesuai dengan sabda Rasulullah:

Jaddiduu iimaanakum qiila wakaifa tujaddidu iimaananas yaa rasuulallaahi? gaala aktsiruu min qauli laa ilaaha illallaahu.

(Baharui olehmu akan imanmu, perbanyaklah mengucapkan perkataan laa ilaaha illallahu (HR. Ahmad).

Untuk itu umat Islam hendaknya mempunyai sikap yang responsif terhadap situasi etis dewasa ini dengan tiga ciri yang menonjol yaitu: (1) adanya pluralisme moral, (2) timbulnya masalah etis baru yang tak terduga, dan (3) adanya kepedulian etis yang universal. Dalam menghadapi situasi etis tsb. diperlukan landasan etis dari firman Allah agar dapat memecahkan masalah dengan melakukan moral reasoning (penalaran akhlak) sehingga dapat menemukan seperangkat moral dari Al Qur'an. Oleh karena itu umat Islam harus memahami bahwa dalam Al Qur'an terdapat ayat-ayat yang $d z o n y$ (yang boleh dan dapat ditafsir), ada pula yang got ' $i$ (tidak mudah atau tidak dapat ditafsirkan, hanya untuk dilaksanakan), ada juga

Ulul Albab, Vol. 4 No. 1, 2003 
kaidah-kaidah yang bersifat historis dan futuristik. Kesemuanya menjadi sumber inspirasi atau titik tolak dalam pengkajian atau penelitian ilmiah yang hasilnya untuk kemaslahatan hidup bersama. Dengan landasan atau tuntunan nilai-nilai moral Islam reformasi pendidikan diharapkan mampu menghasilkan manusia yang pola pikir, dzikir, dan amaliahnya selalu utuh dan bulat dengan acuan seperangkat nilai moral yangmempribadi dalam dirinya sebagai suara hati, sehingga memiliki rasa tanggung jawab terhadap dirinya, bangsa, negara, dan kepada Tuhan Yang Maha Esa.

\section{Bahan Rujukan}

Abdullah, T., \& Karim, M.R. 1991. Metodologi Penelitian Agama: Sebuah Pengantar. Yogya: Tiara Wacana.

Al-Syaibany, O.M.A. 1979. Falsafah Pendidikan Islam. Alih Bahasa Hasan Langgulung. Jakarta: Bulan Bintang.

Amin, A. 1975. Etika (Ilmu Akhlak). Alihbasa: K. H. Farid Ma'ruf. Jakarta: Bulan Bintang.

Azhim, A.A. 1989. Epistemologi dan Aksiologi Ilmu: Perspektif Alquran. Bandung: Rosda.

Djatmika, H.R. 1987. Sistem Ethika Islami (Akhlak Mulia). Surabaya: Pustaka Islam.

Driyarkara. 1980. Driyarkara tentang Pendidikan. Yogyakarta: Kanisius.

Fatimah, I. (Ed.). 1992. Filsafat Islam: Kajian Ontologis, Epistemologis, Aksiologis, Historis, Prospektif. Yogyakarta: Lembaga Studi Filsafat Islam.

Mukrim, A.S. 1988. Pemikiran Islam: Antara Akal dan Wahyu. Alih Bahasa Anwar Wahdi Hasi. Jakarta: Mediyatama Sarana Perkasa.

Muntasir, M.S. 1985. Mencari Evidensi Islam: Analisa Awal Sistem Filsafat, Strategi, dan Metodologi Pendidikan Islam. Jakarta: Rajawali.

Musa, M.Y. 1988. Islam: Suatu Kajian Komprehensif. Terjemahan A. Malik Madaniy, \& Hamim Ilyas. Jakarta: Rajawali Pers.

Najieh, A. 1984. 323 Hadits dan Syair untuk Bekal Da'wah. Jakarta: Pustaka Amani.

Saefuddin, A.M. 1991. Desekularisasi Pemikiran: Landasan Islamisasi. Bandung: Mizan. 